\title{
DUAL COMPLEMENTS FOR DOMAINS OF $\mathbb{C}^{n}$
}

\section{LeV Aizenberg, EliJAh Liflyand AND Aleš NeKVINDA}

Abstract. Let $\Omega \subset \mathbb{C}^{n}$ be a bounded, strictly convex domain and $\widetilde{\Omega}$ be its dual complement. Very few such domains with fully described dual complements have been known. We present new types of domains for which their dual complements can be completely described.

Mathematics subject classification (2010): Primary 32A07; Secondary 32A35, 32A40, 46E30.

Keywords and phrases: Grothendieck-Köthe-da Silva duality, Reinhardt domain, Reinhardt norm, dual complement, variable Lebesgue space, Orlicz space.

\section{REFERENCES}

[1] L. Aizenberg, Carleman's Formulas in Complex Analysis, Kluwer, 1993.

[2] L. Aizenberg, The general form of a continuous linear functional on the space of functions holomorphic in a convex region of $C^{n}$, Dokl. Akad. Nauk SSSR 166 (1966), 1015-1018 (Russian).

[3] L. AIZENBERG, The expansion of holomorphic functions of several complex variables in partial fractions, Sibirsk. Mat. Zh. 8 (1967), 1124-1142 (Russian).

[4] L. Aizenberg, The Duality in Complex Analysis, Proc. Ashkelon Workshop on Complex Function Theory (1996), Israel Math. Conf. Proc. 11 (1997), 27-35.

[5] L. Aizenberg, V. Gotlib, And A. Vidras, Duality for Hardy spaces in domains of $\mathbb{C}^{n}$ and some applications, Complex Anal. Oper. Theory 8 (2014), 1341-1366.

[6] Z. W. Birnbaum AND W. ORLICZ, Über die Verallgemeinerung des Begriffes der zueinander konjugierten Potenzen, Studia Math. 3 (1931), 1-67; Reprinted in: "Władysław Orlicz, Collected Papers", PWN, Warszawa 1988, 133-199.

[7] D. V. Cruz-Uribe And A. Fiorenza, Variable Lebesgue Spaces: Foundations and Harmonic Analysis, Birkhäuser, 2013.

[8] D. V. CRUZ-Uribe AND A. FiorenZA, Introduction to the Variable Lebesgue Spaces, Topics in Variable Lebesgue Spaces and Hyperbolic Equations, Advanced Courses in Mathematics - CRM Barcelona, Birkhäuser, Basel, 2014, 1-90.

[9] M. A. Krasnosel's KiI And Ja. B. RUtickit, Convex functions and Orlicz spaces, translated from the first Russian edition by Leo F. Boron, P. Noordhoff Ltd., Groningen, 1961.

[10] K. Lindberg, On subspaces of Orlicz sequence spaces, Studia Math. XLV (1973), 119-146.

[11] J. Lindenstrauss AND L. TSAFRIRI, On Orlicz sequence spaces, Israel J. Math. 10 (1971), 379390.

[12] L. Maligranda, Orlicz Spaces and Interpolation, Seminars in Math. 5, Univ. of Campinas, Campinas 1989.

[13] L. Maligranda AND W. Wnuk, Landau type theorem for Orlicz spaces, Math. Z. 208 (1991), $57-63$.

[14] L. Maligranda AND W. WNuK, Landau-type theorem for variable Lebesgue spaces, Comment. Math. 55 (2015), 119-126.

[15] L. MALigranda, Hidegoro Nakano (1909-1974) - on the centenary of his birth, in: "Banach and Function Spaces III", Proc. of the Third Internat. Symp. on Banach and Function Spaces (ISBFS2009) (14-17 Sept. 2009, Kitakyushu-Japan), Edited by M. Kato, L. Maligranda and T. Suzuki, Yokohama Publishers 2011, 99-171.

[16] L. Maligranda And L. E. Persson, Generalized duality of some Banach function spaces, Indag. Math. 51 (1989), 323-338. 
[17] W. ORLICZ, Über konjugierte Exponentenfolgen, Studia Math. 3 (1931), 200-211, reprinted in: "Władysław Orlicz, Collected Papers", PWN, Warszawa 1988, 200-211.

[18] S. D. Parashar And B. Choudhary, Sequence spaces defined by Orlicz functions, Indian J. Pure Appl. Math. 25 (1994), 419-428. 